\title{
Conservación in vitro de Dioscorea alata L. clon caraqueño (Dioscoreaceae)
}

\section{In vitro conservation of Dioscorea alata L. clon caraqueño (Dioscoreaceae)}

\author{
Misterbino Borges García ${ }^{1 *}$, Yaimara Alarcón Sánchez¹, Bernard Malaurie², Yanet \\ Hernandez Jerez ${ }^{1}$ y Juan Jose Silva Pupo ${ }^{1}$
}

1 Centro de Estudios de Biotecnología Vegetal, Facultad de Ciencias Agrícolas, Universidad de Granma, Agrícolas, Universidad de Granma, E-mail Misterbino Borges García: mborgesg@udg.co.cu)

2 Institut de Recherche pour le Développement (IRD), UMR DIAPC F-34 000 Montpellier, France. $\begin{array}{ll}\text { Presentado: } & 27 / 07 / 2009 \\ \text { Aceptado: } & 18 / 09 / 2009\end{array}$ $\begin{array}{ll}\text { Aceptado: } & 18 / 09 / 2009 \\ \text { Publicado online: } & 12 / 01 / 2010\end{array}$

\section{Resumen}

El trabajo tuvo como objetivo establecer, para Dioscorea alata L. clon caraqueño, un método eficiente para la conservación in vitro de durante 9 y 12 meses basado en la modificación del medio de cultivo (MS al $75 \%$ + vitaminas MS + sacarosa $30 \mathrm{~g} \cdot \mathrm{L}^{-1}$ + carbón activado $\left.2 \mathrm{~g} \cdot \mathrm{L}^{-1}\right)$ con distintos niveles de manitol y BAP. Los tratamientos consistieron en la adición en el medio de cultivo de manitol $(0 ; 0,5$ y $1,5 \%)$ y BAP $\left(0 ; 0,1 \mathrm{mg}^{-\mathrm{L}^{-1}}\right)$. A los 9 y 12 meses de conservación in vitro se realizaron las siguientes evaluaciones: supervivencia (\%), senescencia foliar (\%), numero de nudos, longitud del vástago, número de microtubérculos. A las 8 semanas de la regeneración de los segmentos nodales (procedentes de vitroplantas conservadas a 9 y 12 meses) en el medio de cultivo (MS al $75 \%$ + vitaminas MS + sacarosa 30 g.L.-1 + carbón activado 2 g.L.-1) se determinó la regeneración de plantas completas (\%), número de nudos, número de hojas y longitud del vástago. A las 5 semanas durante la micropropagación convencional se determinó el número de nudos, número de hojas y la longitud del vástago. Las variantes de cultivo formadas por el medio MS al 75\% + vitaminas MS + sacarosa 30 g. $\mathrm{L}^{-1}+$ carbón activado $2 \mathrm{~g} . \mathrm{L}^{-1}$ y el MS al $75 \%$ + vitaminas $\mathrm{MS}+$ sacarosa $30 \mathrm{~g} . \mathrm{L}^{-1}+$ carbón activado $2 \mathrm{~g} \cdot \mathrm{L}^{-1}+$ BAP $0,1 \mathrm{mg} \cdot \mathrm{L}^{-1}$ permitió de manera efectiva la conservación de vitroplantas a partir de segmentos uninodales de $D$. alata clon caraqueño durante 9 y 12 meses con altos porcentajes de supervivencia, un número significativo de microtubérculos, los menores porcentajes de senescencia foliar y $100 \%$ de regeneración en plantas completas con un crecimiento normal en condiciones de micropropagación.

Palabras clave: ñame, conservación a mediano plazo, cultivo in vitro, manitol, BAP.

\section{Abstract}

In this study, we report an efficient method for conservation in vitro of Dioscorea alata L. clone caraqueño during 9 and 12 months based on the culture medium modification (MS to $75 \%+$ vitamins MS + sucrose $30 \mathrm{~g}^{\mathrm{L}} \mathrm{L}^{-1}+$ activated charcoal 2 g. $\left.\mathrm{L}^{-1}\right)$ with different manitol $(0 ; 0,5$ and 1,5\%) and BAP $(0 ; 0,1$ mg.L-1) levels. At 9 and 12 months of in vitro conservation, the following evaluations were determined: survival (\%), leaf senility (\%), shoot length, buds and microtuber explant count. Plant regeneration (\%), shoot length, leaf number and bud explant count were determined at 8 weeks of the nodal cutting regeneration (from vitroplants conserved for 9 and 12 months) in the culture medium (MS to $75 \%$ + vitamins MS + sucrose $30 \mathrm{~g} \cdot \mathrm{L}^{-1}+$ activated charcoal $2 \mathrm{~g} \cdot \mathrm{L}^{-1}$ ). .Shoot length, leaf number and bud explant count were evaluated at 5 weeks during the conventional micropropagation. The cultivation variants formed by media MS to $75 \%$ + vitamins MS + sucrose $30 \mathrm{~g} . \mathrm{LL}^{-1}+$ activated charcoal 2 g. $\mathrm{L}^{-1}$ and $\mathrm{MS}$ to $75 \%$ + vitamins $\mathrm{MS}+$ sucrose $30 \mathrm{~g} . \mathrm{I}^{-1}+$ activated charcoal $2 \mathrm{~g} \cdot \mathrm{L}^{-1}+\mathrm{BAP} 0,1 \mathrm{mg} \cdot \mathrm{L}^{-1}$ allowed an effective way the conservation of in vitro plants from nodal cutting of clone caraqueño yam during 9 and 12 months with high survival percentages, a significant number of microtubers, smallest leaf senility percentages and $100 \%$ regeneration in whole plants with a normal growth in micropropagation conditions.

Keywords: yam, medium-term conservation, cultivation in vitro, mannitol, BAP.

\section{Introducción}

Los cultivos de raíces y tubérculos desempeñarán una función múltiple en la alimentación del mundo en desarrollo durante las próximas décadas. Para el 2020, más de 2 mil millones de personas de Asia, África y América Latina dependerán de estos cultivos como fuente de alimento, forraje o ingresos económicos. Para los hogares rurales, el valor de las raíces y tubérculos reside en su capacidad de producir más energía digerible por hectárea por día, que cualquier otro producto básico, y en su capacidad de seguir produciendo en condiciones donde otros cultivos fracasan (González, 2003).

La familia Dioscoreaceae comprende más de 600 especies (Ayensu y Coursey, 1972), en particular el género Dioscorea tiene amplia distribución en la zona tropical. Varias especies de Dioscorea acumulan almidón en sus tubérculos y son cultivadas para alimento, mientras que otras son reconocidas por su actividad medicinal. Dioscorea alata L. conocida como ñame es una especie cultivada a gran escala en muchos paises de África tropical, Pacífico y el Caribe, donde constituye una importante fuente de alimento (Mbanaso et al., 2007).
El ñame se reproduce principalmente de forma vegetativa mediante el fraccionamiento de los tubérculos, siendo la principal causa de poca disponibilidad de material de siembra, ya que alrededor del $30 \%$ de los tubérculos son guardados para reproducción. Además a consecuencia de la reproducción vegetativa, las enfermedades son transferidas de un ciclo a otro y de una localidad a otra, incidiendo sobre la productividad del cultivo (Rodriguez et al. 2008).

Las dos principales especies cultivadas son $D$. alata y $D$. rotundata debido a su importancia económica y distribución en el mundo (Arnau et al., 2009).

Los clones de ñame existentes en Cuba y en su colección de germoplasma pertenecen fundamentalmente a las especies $D$. alata, D. rotundata, D. cayenensis, D. esculenta, D. bulbifera $y$ $D$. trifida. Las más extendidas son $D$. alata, $D$. rotundata y $D$. cayenensis (Minagri, 2004). La conservación de los clones con llevan elevados costos de mantenimiento, altos riesgos de erosión genética, ataque de plagas y enfermedades tales como antracnosis, mosaico del ńame, nemátodos, insectos y roedores. 
En Cuba el cultivo de ñame está más extendido en las zonas montańosas de la región central, pero principalmente en la oriental, donde además existe mayor diversidad de especies. En particular para estas zonas el ñame representa un importante alimento debido a su productividad y la posibilidad de su cultivo en sistemas intensivos y agroforestales.

Los primeros trabajos sobre micropropagación in vitro de $D$. alata con empleo de segmentos nodales fueron desarrollados a partir de la década de los años 70 por Ammirato (1976), y Mantell y Haque (1977). Posteriormente fue realizado por primera vez en el IITA (Instituto Internacional de Agricultura Tropical) de Nigeria ( $\mathrm{Ng}$ y Hahn 1985) la conservación in vitro de germoplasma de ñame. Hanson (1986) utilizó manitol 0,2 $\mathrm{M}(3,6 \%)$ como retardante del crecimiento adicionado en el medio de cultivo, logrando con éxito la conservación in vitro de ápices de D. rotundata.

En Cuba, se han desarrollado metodologías de propagación masiva de $D$. alata y de conservación in vitro de germoplasma para seis clones de esta especie hasta por 9 meses (Borges et al. 2003). Esta metodología incluye la utilización de 1,5\% de manitol $+0,1$ mg. $L^{-1}$ de BA, sin embargo, la misma debe ser perfeccionada para la introducción de otros clones de interés agrícola y valor comercial en la región Oriental del país, tal es el caso del clon Caraqueño. Este clon en los últimos 30 años ha estado sometido a una alta erosión genética debido al ataque de plagas y enfermedades mortales como nematodos y antracnosis que ha conducido a una disminución de los rendimientos agrícolas hasta $70 \%$ (Borges et al. 2007) y a la desaparición del mismo en muchas localidades de la región.

Tomando en consideración lo antes expuesto el presente trabajo tuvo como objetivos establecer un método eficiente para la conservación in vitro por crecimiento mínimo de Dioscorea alata clon caraqueño durante 9 y 12 meses basado en la modificación del medio de cultivo con distintos niveles de manitol y BAP, que permita lograr altos porcentajes de regeneración del material conservado in vitro y la micropropagación normal del mismo.

\section{Materiales y métodos}

La investigación fue desarrollada en el laboratorio de Biotecnología del Centro de Estudios de Biotecnología Vegetal de la Facultad de Ciencias Agrícolas en la Universidad de Granma, Bayamo, Cuba en el período comprendido de febrero 2008 a Junio de 2009.

\section{Técnicas y procedimientos generales}

Material vegetal. Se emplearon segmentos uninodales desprovistos de hojas con una longitud aproximada de $15 \mathrm{~mm}$, obtenidos de vitroplantas cultivadas durante 5 semanas (segundo subcultivo), obtenidos de plantas donantes de name (D. alata L.) clon Caraqueño (procedente del Banco de germoplasma del Centro de Estudios de Biotecnología Vegetal de la Universidad de Granma, Bayamo, Cuba) cultivadas durante 35 días en condiciones semicontroladas a partir de fragmentos de tubérculos sanos de alrededor de $100 \mathrm{~g}$ de peso (temperatura de $33 \pm 2{ }^{\circ} \mathrm{C}$, humedad relativa del $70-80 \%$ y luminosidad solar entre 3500 y $4000 \mathrm{~lx}$ con un fotoperíodo de 12 horas.).

Siembra de los explantes y condiciones de cultivo. Los segmentos nodales se cortaron a una longitud de aproximadamente $12 \mathrm{~mm}$ y se colocaron obedeciendo a la polaridad de la planta a razón de un explante por tubo y cuatro por frasco bajo cabina de flujo laminar en condiciones asépticas. Finalmente se colocaron en el cuarto de incubación a una temperatura de $25 \pm$ $1{ }^{\circ} \mathrm{C}$, humedad relativa del $70-80 \%$ y luminosidad solar entre 3500 y 4000 lx con un fotoperíodo de 12 horas.

\section{Conservación in vitro}

Medio de cultivo. Estuvo compuesto por las sales de $\mathrm{Mu}-$ rashige y Skoog (MS) (1962) al 75\%, vitaminas de MS (1962); sacarosa 30 g. $\mathrm{L}^{-1}$, carbón activado 2 g.L $\mathrm{L}^{-1}$, modificado con la utilización de distintos niveles de manitol (\%): BAP (mg.L $\mathrm{L}^{-1}$ ) conformando los siguientes tratamientos: $1(0: 0) ; 2$ (0:0,1); $3(0,5: 0) ; 4(0,5: 0) ; 5(1,5: 0)$ y $6(1,5: 0,1)$. El pH del medio de cultivo se ajustó a 5,8; luego se fundió durante $10 \mathrm{~min}$. en horno microondas, se enfrió hasta $50{ }^{\circ} \mathrm{C}$ y luego se distribuyó en tubos de ensayos de 24 x $150 \mathrm{~mm}$, a razón de $15 \mathrm{~mL}$ por tubo. Finalmente se esterilizó en autoclave durante $25 \mathrm{~min}$. a $1,2 \mathrm{kgf} / \mathrm{cm}^{2}$ atmósfera de presión y $121^{\circ} \mathrm{C}$ de temperatura. Los medios se mantuvieron 3 días como mínimo antes de su uso para descartar cualquier contaminación de los mismos. Los experimentos de laboratorio se desarrollaron bajo condiciones asépticas en cabina de flujo laminar horizontal (IKEM).

\section{Evaluación de la conservación in vitro}

A los 9 y 12 meses de cultivo se realizaron las siguientes evaluaciones:

- Supervivencia (\%) (número de explantes vivos/número total).

- Senescencia foliar (\%) (número de hojas muertas/número total).

- Longitud del vástago (se midió en centímetros con una regla milimetrada, desde la base del explante hasta el último nudo).

- Número de nudos de novo por explante

- Número de microtubérculos.

\section{Regeneración in vitro de los explantes conservados}

Material vegetal. Se emplearon segmentos uninodales de aproximadamente $12 \mathrm{~mm}$ de longitud procedentes de vitroplantas conservadas durante 9 y 12 meses.

Medio de cultivo. Estuvo constituido por las sales de MS al $75 \%$, vitaminas de MS; sacarosa 30 g. $\mathrm{L}^{-1}$ y cisteína $10 \mathrm{mg} . \mathrm{L}^{-1}$. La preparación del medio se realizó como se describió en el experimento anterior. Posteriormente se distribuyó a razón de $20 \mathrm{~mL}$ por frasco $(6 \mathrm{~cm}$ de ancho $\mathrm{x} 9 \mathrm{~cm}$ de altura con un diámetro de la boca de $5,7 \mathrm{~cm}$ ). Finalmente se esterilizó igual al experimento anterior.

\section{Evaluación de la regeneración in vitro}

A las ocho semanas de la regeneración de plantas completas se evaluó:

- Regeneración (\%) (número de explantes que regeneran a plantas completas/número total).

- Longitud del vástago por explante.

- Número de hojas por explante.

- Número de nudos de novo por explante.

\section{Multiplicación in vitro del material regenerado.}

Material vegetal. Se emplearon segmentos nodales de aproximadamente $12 \mathrm{~mm}$ longitud procedentes de las vitroplantas: obtenidas del mejor tratamiento regeneradas a las ocho semanas y sin conservar (testigo). 
Tabla 1. Porcentaje de supervivencia de segmentos uninodales durante 9 y 12 meses de conservación.

\begin{tabular}{ccccc}
\hline $\mathbf{T}$ & $\begin{array}{c}\mathbf{M} \\
\mathbf{( \% )}\end{array}$ & $\begin{array}{c}\text { BAP } \\
\left(\mathbf{m g . L ^ { - 1 }}\right)\end{array}$ & $\mathbf{9}$ meses (\%) & $\mathbf{1 2}$ meses (\%) \\
\hline 1 & 0 & 0 & 99 & $96^{\mathrm{a}}$ \\
2 & 0 & 0,1 & 98 & $95^{\mathrm{a}}$ \\
3 & 0,5 & 0 & 98 & $93^{\mathrm{a}}$ \\
4 & 0,5 & 0,1 & 99 & $94^{\mathrm{a}}$ \\
5 & 1,5 & 0 & 98 & $87^{\mathrm{b}}$ \\
6 & 1,5 & 0,1 & 97 & $88^{\mathrm{b}}$ \\
\hline $\mathrm{EE}$ & & & 0,29 & 0,31 \\
\hline
\end{tabular}

Leyenda: T, Tratamientos; M, Manitol; BAP, bencilaminopurina.

Medias con letras distintas por columnas difieren significativamente para $p<0,05$ según prueba de Tukey. EE, error estándar.

\section{Evaluación de la multiplicación in vitro.}

A las cinco semanas se evaluaron las siguientes variales:

- Longitud del vástago por explante.

- Número de hojas por explante.

- Número de nudos de novo por explante.

\section{Diseño y análisis estadístico.}

Los experimentos de conservación, regeneración y multiplicación in vitro se montaron bajo un diseño completamente aleatorizado con arreglo bifactorial, formado por seis tratamientos con tres repeticiones (100 explantes por cada repetición para determinar los porcentajes de supervivencia, senescencia foliar y regeneración; y 40 explantes por cada repetición para el resto de las variales). Se aplicó una prueba de comparación múltiples de medias de Tukey para el 5\% de probabilidad del error. Todos los análisis estadísticos se procesaron con el paquete Statistica for Windows, versión 8 (StatSoft 2008).

\section{Resultados y discusión Conservación in vitro}

Los resultados del efecto de distintos niveles de manitol y BAP en el medio de cultivo sobre el porcentaje de supervivencia de segmentos uninodales de $D$. alata $\mathrm{L}$ clon caraqueño durante 9 y 12 meses de conservación se muestran en la tabla 1 . A los 9 meses se logran altos valores de supervivencia para cada uno de los tratamientos evaluados sin diferencias significativas entre ellos. Sin embargo, a los 12 meses de conservación in vitro los mayores porcentajes de supervivencia corresponden a los tratamientos del 1 al 4 los cuales difieren de las variantes de cultivo 5 y 6. Esto evidencia que a medida que aumenta la concentración de manitol a partir de $1,5 \%$ se afecta de manera significativa la supervivencia del material vegetal.

En este sentido Malaurie et al (1993) lograron conservar germoplasma de ńame de 6 a 12 meses en un medio compuesto por las sales de Knop modificadas, vitaminas MS (1962) modificadas, 3\% de sacarosa , 2 g. $\mathrm{L}^{-1}$ de carbón activado, 200 $\mathrm{mg} . \mathrm{L}^{-1}$ de glutamina, y para los clones más difíciles de mantener utilizaron un balance de reguladores del crecimiento NAA/BAP de 1 y $0,2 \mathrm{mg} \cdot \mathrm{L}^{-1}$ respectivamente, demostrando que el éxito del proceso de conservación in vitro requiere de un crecimiento lento para limitar los subcultivos y un máximo porcentaje de supervivencia.
Tabla 2. Número de nudos de novo y longitud del vástago de segmentos uninodales durante 9 y 12 meses de conservación.

\begin{tabular}{|c|c|c|c|c|c|c|}
\hline \multirow[b]{2}{*}{$\mathbf{T}$} & \multirow[b]{2}{*}{$\begin{array}{c}\text { M } \\
(\%)\end{array}$} & \multirow[b]{2}{*}{$\underset{\left(\mathrm{mg} \cdot \mathrm{L}^{-1}\right)}{\text { BAP }}$} & \multicolumn{2}{|c|}{9 meses } & \multicolumn{2}{|c|}{12 meses } \\
\hline & & & $\begin{array}{c}\text { Número } \\
\text { de } \\
\text { nudos }\end{array}$ & $\begin{array}{c}\text { Longitud } \\
\text { del } \\
\text { vástago }\end{array}$ & $\begin{array}{c}\text { Número } \\
\text { de } \\
\text { nudos }\end{array}$ & $\begin{array}{c}\text { Longitud } \\
\text { del } \\
\text { vástago }\end{array}$ \\
\hline 1 & 0 & 0 & 13,95 & 7,3 & 15,7 & 8,5 \\
\hline 2 & 0 & 0,1 & 13,94 & 6,5 & 15,6 & 8,7 \\
\hline 3 & 0,5 & 0 & 13,05 & 6 & 14,1 & 6,3 \\
\hline 4 & 0,5 & 0,1 & 13,10 & 5,7 & 15 & 6 \\
\hline 5 & 1,5 & 0 & 12,07 & 5 & 13 & 5,3 \\
\hline 6 & 1,5 & 0,1 & 12,05 & 4,9 & 13,5 & 5,2 \\
\hline $\mathrm{EE}$ & & & 0,05 & 0,07 & 0,05 & 0,07 \\
\hline
\end{tabular}

Leyenda: T, Tratamientos; M, Manitol; BAP, bencilaminopurina.EE, error estándar.

En la tabla 2 se ilustra el efecto de distintos niveles de manitol y BAP en el medio de cultivo sobre el número de nudos de novo y longitud del vástago de segmentos uninodales de Dioscorea alata L. clon caraqueńo durante 9 y 12 meses de conservación. Se observa claramente que no existe un efecto significativo tanto del manitol como del BA sobre estos indicadores de crecimiento y desarrollo del material vegetal durante la conservación in vitro, además se nota una tendencia a la disminución biológica de los mismos a medida que se incrementa las concentraciones de manitol en el medio de cultivo. Este efecto fue observado por Borges et al. (2003) a medida que se incrementaba la concentración de manitol $(1,5,3,5$, y $5,5 \%)$ en el medio de cultivo durante la conservación in vitro de germoplasma de $D$. alata.

En la tabla 3 se observa una influencia de los distintos tratamientos sobre el número de microtubérculos producidos a partir de segmentos uninodales de ñame clon Caraqueño durante 9 y 12 meses de conservación. Los mayores valores se obtuvieron en las variantes 1, 2, 3 y 4 las que difieren de los tratamientos 5 y 6 . Esto indica el efecto importante que ejercen los componentes del medio de cultivo principalmente las sales MS al $75 \%$ de su concentración y la sacarosa 30 g.L. $\mathrm{L}^{-1}$ en la formación de microtubérculos, indicador importante que complementa favorablemente la conservación in vitro y propagación de este clon con todas las ventajas que el mismo ofrece en la posterior recuperación y producción de material vegetal de plantación.

En este aspecto Malaurie et al. (1998) plantearon que la tuberización in vitro puede ser favorecida por diferentes factores en el medio de cultivo (presencia de reguladores del crecimiento,

Tabla 3. Número de microtubérculos de segmentos uninodales durante 9 y 12 meses de conservación.

\begin{tabular}{ccccc}
\hline $\mathbf{T}$ & $\begin{array}{c}\mathbf{M} \\
\mathbf{( \% )}\end{array}$ & $\begin{array}{c}\text { BAP } \\
\left(\mathbf{m g} \cdot \mathrm{L}^{-1}\right)\end{array}$ & $\mathbf{9}$ meses (\%) & $\mathbf{1 2}$ meses (\%) \\
\hline 1 & 0 & 0 & $1,2^{\mathrm{a}}$ & $1,5^{\mathrm{a}}$ \\
2 & 0 & 0,1 & $1,1^{\mathrm{a}}$ & $1,4^{\mathrm{a}}$ \\
3 & 0,5 & 0 & $1^{\mathrm{a}}$ & $1,2^{\mathrm{a}}$ \\
4 & 0,5 & 0,1 & $1,1^{\mathrm{a}}$ & $1,2^{\mathrm{a}}$ \\
5 & 1,5 & 0 & $0,16^{\mathrm{b}}$ & $0,30^{\mathrm{b}}$ \\
6 & 1,5 & 0,1 & $0,11^{\mathrm{b}}$ & $0,25^{\mathrm{b}}$ \\
\hline $\mathrm{EE}$ & & & 0,02 & 0,03 \\
\hline
\end{tabular}

Leyenda: T, Tratamientos; M, Manitol; BAP, bencilaminopurina.

Medias con letras distintas por columnas difieren significativamente para $p<0,05$ según prueba de Tukey. EE, error estándar. 
Tabla 4. Porcentaje de senescencia foliar de segmentos uninodales durante 9 y 12 meses de conservación.

\begin{tabular}{ccccc}
\hline $\mathrm{T}$ & $\begin{array}{c}\mathrm{M} \\
(\%)\end{array}$ & $\begin{array}{c}\text { BAP } \\
\left(\mathrm{mg}^{-1}\right)\end{array}$ & 9 meses $(\%)$ & 12 meses (\%) \\
\hline 1 & 0 & 0 & $14^{\mathrm{b}}$ & $19,5^{\mathrm{c}}$ \\
2 & 0 & 0,1 & $15^{\mathrm{b}}$ & $20,5^{\mathrm{c}}$ \\
3 & 0,5 & 0 & $27^{\mathrm{a}}$ & $31^{\mathrm{b}}$ \\
4 & 0,5 & 0,1 & $22^{\mathrm{a}}$ & $32^{\mathrm{b}}$ \\
5 & 1,5 & 0 & $26^{\mathrm{a}}$ & $49^{\mathrm{a}}$ \\
6 & 1,5 & 0,1 & $23^{\mathrm{a}}$ & $48^{\mathrm{a}}$ \\
\hline EE & & & 0.14 & 0.24 \\
\hline
\end{tabular}

Leyenda: T, Tratamientos; M, Manitol; BAP, bencilaminopurina.

Medias con letras distintas por columnas difieren significativamente para $p<0,05$ según prueba de Tukey. EE, error estándar.

composición mineral, concentración de sacarosa) y en las condiciones de cultivo (fotoperíodo, termoperíodo).

También Klu (2002) señaló que la microtuberización es un proceso que favorece la producción de material de plantación así como su conservación, facilitando el intercambio de germoplasma, mientras que Balogun (2009) plantea que los microtuberculos producidos a partir de plántulas in vitro tienen una mayor vida útil debido a la latencia, son más resistentes y menos voluminosos que las plántulas.

La influencia de los distintos niveles de manitol y BAP en el medio de cultivo sobre el porcentaje de senescencia foliar de segmentos uninodales de ńame clon caraqueño durante 9 y 12 meses de conservación (tabla 4) arrojaron valores significativamente superior para los tratamientos: 3; 4; 5 y 6 (9 meses), y 5; 6 seguido de 3; 4 (12 meses). Esto indica que a medida que se aumenta la concentración de manitol en el medio de cutivo se incrementa de forma significativa el deterioro y necrosis del tejido foliar, lo cual se manifiesta de forma más diferencial al cabo de los 12 meses de conservación.

Resultados semejantes fueron alcanzados por Borges et al. (2003) los cuales determinaron que al aumentar la concentración de manitol $(1,5 ; 3,5$ y $5,5 \%)$ en el medio de cultivo durante la conservación in vitro de germoplasma de $D$. alata durante 9 meses, se incrementaba el deterioro y muerte de los tejidos, y en particular el foliar.

Por otra parte estos resultados no coinciden con los obtenidos por Espinosa et al. (2002) quienes lograron exitosamente la conservación in vitro durante 12 meses de cuatro clones de boniato

Tabla 5. Regeneración in vitro de segmentos uninodales a las ocho semanas procedentes del material conservado durante 9 meses.

\begin{tabular}{cccccc}
\hline $\mathbf{T}$ & $\begin{array}{c}\mathbf{M} \\
\mathbf{( \% )}\end{array}$ & $\begin{array}{c}\text { BAP } \\
\left(\mathbf{m g} \cdot \mathrm{L}^{-1}\right)\end{array}$ & $\begin{array}{c}\text { Número } \\
\text { de nudos }\end{array}$ & $\begin{array}{c}\text { Longitud } \\
\text { del } \\
\text { vástago }\end{array}$ & $\begin{array}{c}\text { Número de } \\
\text { hojas }\end{array}$ \\
\hline 1 & 0 & 0 & 3 & 2,3 & 3,6 \\
2 & 0 & 0,1 & 2,8 & 2,2 & 3,4 \\
3 & 0,5 & 0 & 2,9 & 1,92 & 3,3 \\
4 & 0,5 & 0,1 & 2,7 & 1,94 & 3,2 \\
5 & 1,5 & 0 & 2,7 & 2 & 3,5 \\
6 & 1,5 & 0,1 & 2,7 & 2,3 & 3,5 \\
\hline & $\mathrm{EE}$ & & 0,019 & 0,035 & 0,05 \\
\hline
\end{tabular}

Leyenda: T, Tratamientos; M, Manitol; BAP, bencilaminopurina.EE, error estándar. en el medio MS suplementado con sacarosa $0,5 \%$, manitol $2 \%$ y tiamina $1 \mathrm{mg} \mathrm{L}^{-1}$.

\section{Regeneración in vitro}

A las ocho semanas las yemas de segmentos nodales, procedentes de vitroplantas conservadas durante 9 y 12 meses en los distintos tratamientos reanudaron su crecimiento en el medio de cultivo MS al $75 \%$ con un $100 \%$ de regeneración en plantas completas. Estos resultados son semejantes a los alcanzados por Borges et al. (2004) durante la regeneración y multiplicación de segmentos uninodales de diferentes clones de ñame ( $D$. alata L.) conservados in vitro durante 9 meses en un medio de cultivo con distintos niveles de manitol $(1,5 ; 3,5 ; 5,5 \%)$, BAP $(0 ; 0,1$ mg. $\left.\mathrm{L}^{-1}\right)$ y carbón activado $\left(0 ; 2\right.$ g. $\left.\mathrm{L}^{-1}\right)$ donde alcanzaron $100 \%$ de regeneración en plantas completas en las variantes de cultivo procedentes del medio de conservación con manitol 1,5\%, BAP $\left(0,1 ; 1 \mathrm{mg} . \mathrm{L}^{-1}\right)$ y carbón activado 2 g. $\mathrm{L}^{-1}$.

Los resultados de regeneración obtenidos en esta investigación demuestran la efectividad de los distintos tratamientos de conservación evaluados tanto a 9 meses como a 12 meses, y en este último tiempo, principalmente para los tratamientos 1,2 3 y 4 en los cuales se alcanzan significativamente los mayores porcentajes de supervivencia (tabla 1). Esto corrobora por una parte lo seńalado por Espinosa et al. (2003) que propusieron el porcentaje de supervivencia y recuperación del material vegetal conservado como los criterios a tener en cuenta al decidir la validez de una metodología para la conservación in vitro de especies vegetales. Por otro lado Mesa et al. (1995) que consideran el fenómeno de regeneración de órganos o plantas completas como un elemento determinante para establecer un método eficiente de micropropagación acelerada o conservación in vitro de variedades y especies.

Nair y Chandrababu (1994), en la regeneración de yemas de segmentos nodales de $D$. alata y $D$. rotundata en un medio MS sin hormonas, encontraron un 100\% de plantas completas regeneradas, procedentes de la conservación durante 12 meses en el medio MS suplementado con 3\% de manitol.

En la tabla 5 y 6 se muestran los principales indicadores del crecimiento y desarrollo de vitroplantas a las ocho semanas de cultivo obtenidas de segmentos uninodales conservados durante 9 y 12 meses en sus distintos tratamientos. Se aprecian valores sin diferencia significativa entre las distintas variantes de cultivo y similares a los alcanzados durante la multiplicación convencional a las cinco semanas de cultivo, esto evidencia que al cabo de las

Tabla 6. Regeneración in vitro de segmentos uninodales a las ocho semanas procedentes del material conservado durante 12 meses.

\begin{tabular}{cccccc}
\hline $\mathbf{T}$ & $\begin{array}{c}\mathbf{M} \\
\mathbf{( \% )}\end{array}$ & $\begin{array}{c}\text { BAP } \\
\left(\mathbf{m g .} \mathbf{L}^{-1}\right)\end{array}$ & $\begin{array}{c}\text { Número de } \\
\text { nudos }\end{array}$ & $\begin{array}{c}\text { Longitud } \\
\text { del vástago }\end{array}$ & $\begin{array}{c}\text { Número } \\
\text { de hojas }\end{array}$ \\
\hline 1 & 0 & 0 & 2,9 & 2,2 & 3,5 \\
2 & 0 & 0,1 & 2,7 & 2,1 & 3,4 \\
3 & 0,5 & 0 & 2,9 & 1,9 & 3,2 \\
4 & 0,5 & 0,1 & 2,7 & 2 & 3,1 \\
5 & 1,5 & 0 & 2,6 & 2,2 & 3,4 \\
6 & 1,5 & 0,1 & 2,7 & 2,2 & 3,4 \\
\hline & EE & & 0,02 & 0,04 & 0,05 \\
\hline
\end{tabular}

Leyenda: T, Tratamientos; M, Manitol; BAP, bencilaminopurina.EE, error estándar. 
Tabla 7. Multiplicación del material vegetal procedente del mejor tratamiento de conservación durante 9 meses a los 35 días de cultivo.

\begin{tabular}{cccc}
\hline Tratamientos & $\begin{array}{c}\text { Número de } \\
\text { nudos }\end{array}$ & $\begin{array}{c}\text { Longitud del } \\
\text { vástago }\end{array}$ & $\begin{array}{c}\text { Número de } \\
\text { hojas }\end{array}$ \\
\hline 1 & 2,8 & 2,2 & 3,3 \\
Testigo & 2,7 & 2,3 & 3,4 \\
\hline EE & 0,04 & 0,05 & 0,05 \\
\hline
\end{tabular}

Tratamientos: 1, mejor tratamiento de conservación; Testigo, material sin conservar (vitroplantas en segundo subcultivo). EE, error estándar.

8 semanas de cultivo el material vegetal procedente de la conservación recupera su capacidad de micropropagación normal.

Estos resultados son similares a los alcanzados por Borges et al.(2004) durante la regeneración y multiplicación de segmentos uninodales de diferentes clones de ñame ( $D$. alata L.) conservados in vitro durante 9 meses en un medio de cultivo con distintos niveles de manitol $(1,5 ; 3,5 ; 5,5 \%), \operatorname{BAP}(0 ; 0,1$ mg. $\left.\mathrm{L}^{-1}\right)$ y carbón activado $\left(0 ; 2\right.$ g. $\left.\mathrm{L}^{-1}\right)$ donde lograron a las ocho semanas en las variantes de cultivo procedentes del medio de conservación con manitol 1,5\%, BAP $\left(0,1 ; 1 \mathrm{mg} . \mathrm{L}^{-1}\right)$ y carbón activado $2 \mathrm{~g}$. $\mathrm{L}^{-1}$ indicadores de crecimiento y desarrollo del material vegetal similar al crecimiento de $D$. alata en condiciones normales de micropropagación.

Resultados comparables han sido obtenidos en la multiplicación in vitro de $D$. alata a partir de yemas de segmentos nodales, por diferentes autores (Mantell y Haque 1977; Borges et al., 2004; Myouda et al. 2005; Royero et al., 2007; Salazar y Hoyos, 2007)

\section{Multiplicación in vitro}

Los valores de los indicadores de crecimiento y desarrollo (longitud del vástago, número de nudos de novo y hojas) durante la multiplicación in vitro del material procedente del mejor tratamiento (MS al 75\% sin adición de manitol y BAP) que dio lugar al $100 \%$ de regeneración de plantas completas después de su conservación in vitro por un periodo de 9 y 12 meses (Tabla 7 y 8 ) con altos porcentajes de supervivencia de 99 y 96\% (Tabla 1) respectivamente, no presentaron diferencias significativas con el testigo. Esto indica que a las 5 semanas se logra la micropropagación tradicional de manera normal y que el método de conservación empleado es aplicable a $D$. alata clon caraqueño.

Los resultados alcanzados concuerdan con los obtenidos por diferentes autores (Mantell y Haque 1977; Borges et al., 2004; Royero et al., 2007) que han desarrollado y perfeccionado distintas metodologías para micropropagación in vitro de $D$. alata $\mathrm{L}$ alcanzando como promedio valores similares para estos parámetros de crecimiento y desarrollo en condiciones normales de multiplicación.

Por otra parte resultados satisfactorios han sido obtenidos por Espinosa et al. (2002) en la conservación in vitro durante 12 meses, de segmentos nodales de boniato en el medio basal MS suplementado con sacarosa $0,5 \%$, manitol $2 \%$ y tiamina $1 \mathrm{mg.L}$ ${ }^{1}$, alcanzando altos porcentajes de supervivencia y recuperación del material, sin cambios morfológicos aparentes del material conservado durante la micropropagación.

Finalmente podemos plantear que los medios de cultivos compuestos por las sales MS al 75\% + sacarosa 30 g.L.-1 + carbón
Tabla 8. Multiplicación del material vegetal procedente del mejor tratamiento de conservación durante 12 meses a los 35 días de cultivo.

\begin{tabular}{cccc}
\hline Tratamientos & $\begin{array}{c}\text { Número de } \\
\text { nudos }\end{array}$ & $\begin{array}{c}\text { Longitud del } \\
\text { vástago }\end{array}$ & $\begin{array}{c}\text { Número de } \\
\text { hojas }\end{array}$ \\
\hline 1 & 2,6 & 2,1 & 3,2 \\
Testigo & 2,7 & 2,2 & 3,3 \\
\hline EE & 0,04 & 0,05 & 0,06 \\
\hline
\end{tabular}

Tratamientos: 1, mejor tratamiento de conservación; Testigo, material sin conservar (vitroplantas en segundo subcultivo). EE, error estándar.

activado 2 g. $\mathrm{L}^{-1}+$ BAP 0,1 mg. $\mathrm{L}^{-1}$ y sin adición de BAP permiten de manera efectiva la conservación de vitroplantas a partir de segmentos uninodales de ńame clon caraqueńo durante $9 \mathrm{y}$ 12 meses con altos porcentajes de supervivencia, los menores porcentajes de senescencia foliar, $100 \%$ de regeneración en plantas completas, un número significativo de microtubérculos y parámetros normales de crecimiento en condiciones de micropropagación.

\section{Agradecimientos}

Esta investigación fue realizada satisfactoriamente gracias al proyecto internacional Apoyo al desarrollo de la Biotecnología Vegetal y la Agricultura Urbana financiado por la Diputación Foral de BizKaia y la asociación Euskadi-Cuba. También fue posible por la capacitación científico-técnica recibida por el equipo de investigación en la Unidad DIAPC del Centro IRD/ CIRAD de Montpellier, Francia. A todos mis más sinceros agradecimientos.

\section{Literatura citada}

Ammirato, P. V. (1976): Hormonal control of tuber formation incultured axillary buds of Dioscorea bulbifera and Dioscorea alata . Plant Physiology, 57 (5) suppl. 66 pp.

Arnau G., A. Nemorin, E.E. Maledon\& K. Abraham. 2009. Revision of ploidy status of Dioscorea alata L.(Dioscoreaceae)by cytogenetic and microsatellite segregation analysis. Theor Appl Genet 118:1239-1249.

Ayensu E.S. \& D.G. Coursey 1972. Guinea yams. The botany, ethnobotany, use and possible future of yams in West Africa. Econ bot 26:301-318

Baco M.N., G. Biaou, F. Pinton \& J.P. Lescure. 2007. Les savoirs paysans traditionnels conservent-ils encore l'agrobiodiversité au Bénin. Biotechnol. Agron. Soc. Environ. 11 (3), 201-210.

Balogun M.O. 2009. Microtubers in yam germplasm conservation and propagation: The status, the prospects and the constraints. Biotechnology and Molecular Biology Reviews 4 (1):001-010.

Borges M., S. Meneses, J. Vazquez \& M. García. 2003. Conservación in vitro de germoplasma de Dioscorea .alata L. por crecimiento mínimo. Plant Genetic Resources Newsletter, No. 133: 8-12.

Borges M., W. Ceiro, S. Meneses \& N. Aguilera. 2004. Regeneration and multiplication of Dioscorea alata L germplasm maintained in vitro. Plant Cell, Tissue and Organ Culture 76: 87-90.

Borges M., Y. Perez \& D. Zayas. 2007. Efecto de diferentes formulaciones de vitaminas en la multiplicación in vitro del ñame clon caraqueño. Biotecnología Vegetal. 3 (3): 160 - 168.

Espinosa A., L. Salas, O. Gonzalez \& J.J. Silva. 2002. Empleo del ácido abscísico, manitol y la disminución de las sales del medio de cultivo en la conservación in vitro de Ipomoea batatas. Biotecnología Vegetal 2 (1): 49-42. 
Espinosa A., O. Gonzalez \& J.J. Silva. 2003. Conservación in vitro de clones de boniato en condiciones de crecimiento mínimo. Biotecnología Vegetal Vol. 3, No 1: 37-41.

González Y. C. 2003. Caracterización morfológica y molecular de genotipos de Dioscorea alata y D. trifida del Instituto de Investigación Agropecuaria de Panamá, IDIAP y CATIE, Costa Rica". Tesis de Magíster Scientiae. CATIE. 93 pp.

Hanson J. 1986. Methods of storing tropical root crop germplasm with special reference to yam. FAO/IBPGR Plant Genetic Ressources Newsletter 64: 24-32.

Klu G. Y. P. 2002.Conservation of Dioscorea rotundata: Effect of Basal Medium Type and Naphthalene Acetic Acid on Growth and Microtuberization. West African Journal of Applied Ecology, vol. 3, 99 - 104.

Mantell, S.H. \& S.Q. Haque. 1977. Three techniques for rapid clonal propagation of White Lisbon yam (Dioscorea alata L.). Nouv. agron. Antille-Guyane, 1, (3/4), 413-427.

Malaurie B. 0., R .Pungu, M. Dumont \& M.F. Trouslot. 1993. The creation of an in vitro germplasm collection of yam (Dioscorea spp.) for genetic resources preservation. Euphytica 65: 113-122.

Malaurie B., M.F. Trouslot \& J. Berthaud. 1998. Conservation et echange de germoplasme chez les ignames (Dioscorea spp.). En: J. Berthaud, N. Bricas, J.L. Marchand (Eds). L'igname, plante seculaire et culture d'avenir, Montpellier, France p 135 - 161.

Mbanaso E.N.A., Chukwu L.I. \& M.U.A. Opara. 2007. In vitro basal and nodal microtuberization in yam shoot cultures (Dioscorea rotundata poir, cv. Obiaoturugo). under nutritional stress conditions. African Journal of Biotechnology 6(21): 2444-2446.

Mesa A.R., G. Lajonchere \& O. Toral. 1995. El cultivo in vitro en el mejoramiento de pastos y forrajes. Micropropagación y conservación de germoplasma. Revista Pastos y Forrajes, 18:1-10.
Minagri. 2004. Instructivo técnico del cultivo del ñame. La Habana, $16 \mathrm{pp}$.

Murashige, T. \& F. Skoog. 1962. A revised medium for rapid growth and bioassays with tobacco tissue cultures. Physiol. Plant. 15: 473 - 497.

Myouda T., A. Sanada, S. Fuji \& T. Natsuaki. 2005. Propagation of greater yam (Dioscorea alata L.) using shoot apex and nodal segment cultures combined with virus detection by RT-PCR. SABRAO Journal of Breeding and Genetics 37(1) $1-11$.

Nair N.G. \& S. Chandrababu. 1994. A slow growth medium for in vitro conservation of edible yams, Journal of Root Crops 20(1): $68-69$.

Ng, S.Y.\& S.K. Hahn.1985. Application of tissue culture to tuber crops at IITA. In : Biotechnology in international research, IRRI, Manila, 29-40.

Rodriguez M., J. Matehus, A. Gersti \& M.A. Santana. 2008. Identificación del agente causal de una bacteriosis en ñame (Dioscorea alata L.). Interciencia. Volumen 33(7): 1-11.

Royero M., T.E. Vargas \& M. Oropeza. 2007. Micropropagación y organogénesis de Dioscorea alata (ñame). Interciencia. Vol. 32. No. 4. 11p.

Salazar R., \& R.A. Hoyos. 2007. Multiplicación y tuberización in vitro de ñame (Dioscorea alata L.) en sistema de inmersión temporal. Rev. Fac. Nal. Agr. Medellín. Vol. 60, No. 2. p. 3907-3921.

StatSoft, Inc. 2008. Statistica for Windows. Release 8.0. StatSoft, Inc. Tulsa, OK. 